\title{
Father-Daughter Attachment Pattern and its Influence on
}

\section{Daughter's Development}

\author{
Naina Jain ${ }^{1}$
}

\section{ABSTRACT:}

The objective of the paper is to study the influence of father-daughter attachment pattern on daughter's development. This is a theoretical paper, wherein patterns are drawn out of attachment theory and existing review of literature on father-daughter attachment pattern. The discussion around the theory and literature shows that the presence of secure attachment between daughter and father has positive influence on daughter's development. However, insecure attachment can negatively influence the development of daughter. An attempt is made to see father-daughter attachment pattern from Indian perspective.

Keywords: father-daughter; attachment; development.

\section{INTRODUCTION:}

Father-daughter attachment pattern and its influence on daughter's development Father-daughter dyad is less explored relationship in the field of parent-child research (carter, 2002; katorski, 2003). Many studies have focused on the mother-child relationship, and very few have focused on father-child relationship (Scheffler \& Naus, 1999).But now it seems that interest is growing in this area too. This limited availability of research in this area as well as the interest in knowing the quality of relationship shared by father and daughter especially from Indian perspective became the source of motivation for writing this paper.The presence of different attachment pattern and its influence on the development of daughter is understood with the help of attachment theory and existing literature, and is followed by some patterns coming out of the theory and literature.

"Attachment is the strong, affectionate tie we have with special people in our lives that leads us to experience pleasure and joy when we interact with them and to be comforted by their nearness in times of stress" (Berk, 2013). The psychoanalytic perspective suggests that mother is the primary attachment figure and lays the foundation of all later relationship. "Contemporary research indicates that-although parent-infant bond is vitally important-later development is influenced not just by early attachment experiences but also by the continuing quality of parentchild relationship"(Berk, 2013).

\footnotetext{
${ }^{1}$ M.A. psychology, department of psychology, north campus, university of Delhi
} 


\section{Father-daughter attachment pattern and its influence on daughter's development}

"Bowlby (1969) gave the ethological theory of attachment, which recognizes the infant's emotional tie to the caregiver as an evolved response that promotes survival" (Berk, 2013).He retained the psychoanalytical idea that primary attachment pattern influence attachment patterns of later relationships and gave the concept of internal working model.

“According to bowlby (1980), out of their (children's) experience during the first two years of life, children develop an enduring affectionate tie that they can use as a secure base in the parent's absence. This image serves as an 'internal working model', or set of expectations about the availability of attachment figures, their likelihood of providing support during times of stress, and the self's interaction with those figures. The internal working model becomes a vital part of personality, serving as a guide forall future close relationship. Consistent with the idea, an early study shows that securely attached toddlers looked longer at a video of an unresponsive caregiver (inconsistent with their expectations) than a video of a responsive caregiver. Insecurely attached toddlers could not distinguish between the two" (Berk, 2013).

The most commonly recognized patterns of attachment are given by Ainsworth et al., (1978); "secure attachment - the infant use the parent as a secure base, avoidant attachment- the infant seem unresponsive to the parent when she/he is present, resistant attachment- before separation, infants seek closeness to the parent and often fail to explore, disorganized/disoriented attachment- this pattern reflects greatest insecurity" (Berk, 2013).Secure attachment can be understood as a pattern of attachment that is shared between father and daughter in which both father and daughter are communicative; emotionally close and more engaged. Whereas insecure attachment pattern can be understood as a pattern of attachment in which, father and daughter are relatively less communicative; less emotionally close and less engaged. Also the absence of father would mean insecure attachment pattern where the daughter has not get the option only to interact with the father. This understanding of the words 'secure and insecure attachment' can be maintained throughout this paper.

According to Nielsen (2012), "average fathers and daughters are less communicative, less engaged, and less intimate than mothers and daughters. The relationship of fathers and daughters are consequently more unstable and fragile." This suggests that average daughter and father relations are insecurely attached. "Poorly fathered girls are generally plagued with a host of problems throughout their lives-problems that too often have a negative impact on their children as well"(Nielsen, 2012).

This pattern of insecure attachment between father and daughter can be observed in many cultures, including India and for e.g. USA, for instance, "Kakar (1992) claims that Indian infants (both boys and girls) are more closely attached to their mothers, and remain until the age of four or five, and the father does not play a significant role at that time" (Sharma, 2003). But some researches do not find so, for example.,"roopnarine, talukder, jain, joshi and srivastav (1990, 1992) have found out that Indian men(middle-income from dual-earner family in New Delhi) are active participants in their young children's lives" (Sharma, 2003). These two views from the 
Indian context somewhere imply that there existed this tendency in some fathers to involve more in their daughter's life about two decades ago. This also suggest that now more and more number of fathers have started to be more involved and attached to their daughters than in the past (of course many factors can influence this hypothesis, such as SES status, awareness and education level). Thus this shift makes the study of the topic more relevant in order to understand if there is any positive impact of secure attachment between father and daughter on daughter's development.

This paper aims at finding the influence of secure and insecure attachment pattern present between father and daughter on daughter's development. This paper also seeks to know the reasons of father's less involvement with their daughters and the decreasing level of involvement as the daughter move towards adolescence and also if any gender difference exist in the involvement level of father with his children. This paper also looks at the cultural difference (if any) present in the quality of relationship shared between father and daughter.

\section{REVIEW OF LITERATURE}

Researchers suggest that a securely attached daughter is more likely to have higher communication satisfaction and communication adaptability in general. According to Carter(2002)"securely attached daughters have higher communication satisfaction than insecure daughters. On the other hand fathers "satisfaction level does not differ among attachment styles." Also according to Katorski (2003)"secure attachment pattern between a daughter and father is significantly related with communication satisfaction and communication adaptability." But the researcher could not find out any significant relation between childhood attachment pattern and adult attachment pattern. However, another researcher could find out a significant relationship between childhood and adult attachment pattern. Williams (2006) " suggest that secure attachment pattern with father in childhood leads to secure adult attachment pattern whereas insecure attachment with father in childhood can lead to insecure adult attachment pattern." Thus daughters carry the quality of relationship that they share with their father forward with their romantic partner. Also"Hazan and shaver (1987) clearly suggest that childhood attachment patterns are relatively same in adulthood, and that romantic attachment pattern is significantly related to experience with parents"(Grogan).

Quality of father-daughter relationship also impacts daughter's social development. For instance, research done by Pearce (2009) suggests that "daughter-father attachment in adulthood is significantly related with daughter's emotional regulation in general." Also, according to pleck (1997) "Fathers tend to interact less with daughters than sons at all ages, but particularly during adolescence. Since fathers give infants and young children different types of social cues, having an involved father appears to aid a child's early development of interpersonal differentiation, social competence, and social understanding." This research by pleck suggests that the level of involvement decreases as the daughter grows and move to the stage of adolescence, also this research informs that their exist gender difference in the way fathers get involve and attach to their children. 
More involved fathers provide another benefit to their daughters; physiological benefit. A study conducted by Vanderbilt University underlines the influence of father-daughter relationship on puberty. According to research from Vanderbilt University, "girls who had close, positive relationships with their fathers during the first five years of life tended to reach puberty later than girls who had more distant relationships with their fathers". In addition, the University of Oxford researchers noted that "girls who had more involved fathers were less likely to face mental health problems later in life."

As the secure attachment shows the positive impact on daughter's development, insecure attachment also shows its negative impact on daughter's development. Ankita knight in her paper suggested "that girls whose early childhood is characterized by father-absence tend to grow up with the belief that the male parental role is unimportant and unreliable."According to another research conducted by Jackson (2010) "fatherless women consider themselves to be open, able to easily express themselves, independent and even dominant in their romantic relationships; yet despite holding these characteristics, these women remained in dysfunctional relationships for long periods of time. Further, when self-silencing did occur, it was because they did not want to not 'push' their significant others away. There was also a tension between wanting to hold a dominant role in their romantic relationships and also being attracted to men who hold stereotypical male gender roles. Hence, there was a tension with agreeing or disagreeing with these socially constructed gender roles."Also the researcher found in another study that "respondents who had negative relationships with their fathers self-disclosed less in their romantic relationships and self-silenced more, hid their feelings more, and privileged their romantic partners in communication interactions." This study very comprehensively points out that how the daughter carries the burden of negative relationship that she shares with her father onto the relationship that she shares with her romantic partner.

Another study by boothroyd and perrett (2008) found out the effect of father's absence or poor parent-daughter relationship on the preference of the romantic partner. "Daughters who reported low quality relationship with parents during childhood showed lower masculinity preference. It can be predicted that early family stress should be associated with reduced ability to compete for mates and thus preference for less masculine men."

The literature review, attachment theory and personal observation are used to cull out some patterns explicitly or implicitly visible in the paper. These patterns are discussed and examined with an attempt to understand in depth the quality of relationship shared between father and daughter.

\section{DISCUSSION}

All the above researches and attachment theory signify the importance of father and daughter attachment throughout the life. It is a possibility that father's image as an attachment figure remain active and alive in the daughter's whole life. The effect of this relationship can be seen in many areas of development in daughter's life. From the above information an understanding can 
be drawn about the attachment pattern shared between father-daughter and its influence on daughter's development.

\section{Fathers interact less with daughters at all ages}

According to pleck (1997), this is true, that "fathers interact less with their daughters as compared to their sons, at all ages, especially at adolescence." Suggesting, that gap in interaction between father and daughter increases as daughter grows and reaches the stage of adolescence. The reason behind this gap seems not to be much empirically explored. But it can be predicted that as the children, both sons and daughters, grow and reach the stage of puberty, parents take charge of molding their children in stereotypical gender role. Thus usually mother take the responsibility of her daughter, tend to interact more with the daughter, get the daughter involve more with her in feminine tasks (e.g., cooking, dressing) and tend to prepare the daughter for the stereotypical roles, which is expected out of her. And father seems to take the charge of son, teaches him stereotypical masculine roles that is expected out of him. Thus this can be a reason, why, fathers start interacting less with their daughters, and possibly mothers would be interacting less with their sons. This reason might be supported by a research, which found out that fathers stimulate their son's intellectual and verbal growth more than their daughter's (Veneziano, 2004).

On the other hand, most of the Indian families in which the father is viewed as the bread-winner only whose main work is to earn the money tend to support the notion of almost no or little interaction between fathers and daughters, especially in adolescence. May be because they follow very strong stereotypical roles and suppose that their daughters will also follow the same feminine role and therefore tend to unconsciously leave the responsibility of their daughters on their wives and take charge of their sons. As pointed out by "kakar (1992) children are not close to their father in early childhood" (Sharma, 2003), seems to suggest that daughters tend to continue this pattern in their later life as well whereas sons tend to start interacting with their father. This discussion draws another important point that there exist gender differences in the way fathers interact with their children.

\section{Negative influence of uninvolved father on daughter's development}

"There are host of problems that this poor relationship between father and daughter carries with it throughout the life of daughter", as suggested by Nielsen (2012). It can be implied from above researches that father's absence or insecure attachment between father and daughter will yield $n$ numbers of negative influence on daughter's development, for instance, it harms daughter's psycho-social development the most. "Poorly fathered daughters have low social competence, social understanding, self-esteem, communication satisfaction, interpersonal differentiation, emotional regulation and communication adaptability" (Pleck, 1997; Williams, 2006; Carter, 2002; Pearce, 2009; Katorski, 2003).The question of importance here is that, why there is such a negative impact of father's absence on daughter's development? The reason lies in the fact that "fathers (Indian) are more involved with their children in tasks such as planning, competing"(yeung, 2010), "problem solving" (Williams, 2006) than mothers, thus providing the environment that foster social competence and social understanding in children which mother 
might not alone can teach. The absence of father and his teachings in daughter's life might become disadvantaged for the daughter's development. It seems that if daughters are never exposed to these learning and stimulations and which if never provided to her from any other source (e.g. workshops) would hamper their growth and might make them disadvantaged in these domains of development for lifetime.

Self-esteem is another important aspect of development which seems to be disrupted by the absence of father. "Adolescence is a critical phase in the development of self-esteem. It is characterized by the development of increased cognitive capacities for logical and abstract thinking. This allows adolescents to perceive and reflect on the self as existing separate and apart from others. These cognitive developments result in substantial, increased differentiation between self and an individual's self-representations" (Williams, 2006). Adolescents seem to carry this self-esteem to their adulthood, through internal working model. According to Williams (2006), "Knowledge of their father gives them an identity, builds their self-esteem and sense of self, thus providing a form of reference for the child as future parent/adult."Thus it implies that no such reference is generated in adolescent's mind, which results in confused identity and confused self-concept, and ultimately confused self-esteem. Thus it seems that father's absence at this crucial stage has a detrimental effect on daughter's development of self-esteem. It can be estimated that insecurely attached daughter would have a weaker self-esteem than a securely attached daughter.

\section{Father-daughter attachment pattern predicts adult attachment pattern}

It seems a widely believe notion that girls choose their romantic partners inhabiting similar characteristics as their fathers inhabit. Why so? Why father as an attachment figure is so much endured by the daughters? Father is supposed to be the first male attachment figure in daughter's life which has such a large influence on daughter's set of expectation of an ideal male. This internal working model of perfect father figure seems to be carried forward while finding a mate. Grogan suggest, that "McElwain and volling (2004) revealed that by the age of four, effects of attachment, security, and parental sensitivity experienced during infancy are manifested in friendship quality. Their research suggests attachment, security, and parental sensitivity are catalysts for development of trust, happiness, and communication experienced in future relationships. Those individuals who demonstrate more positive and loving relationships with parents experience more trust, comfort, and communication with romantic partners."

However also, the insecurely attached daughter tends to carry the negative influence of their relationship with father into the relationship with their romantic partner. As shown in above researches by, for instance, Jackson (2010), the young daughter seems to be confused with her role and her partner's role, she tend to live in dysfunctional relationship, without possibly, knowing the reason. May be because she could never get a chance to form an ideal image of a male, or if she could make an image, it was distinct from the father figure, which seem not to be helpful in building up a structured internal working model. This disruption in set of expectations might influence the dysfunction in romantic relationship and the preference for the romantic partner. 


\section{Positive impacts of secure attachment with father on daughter's overall development}

As the absence of father has negative impact on daughter's development, his presence has positive impacts on her development. "Securely attached daughters have communication satisfaction, communication adaptability, higher self-esteem, social competence, social understanding, interpersonal differentiation and emotional regulation" (Pleck, 1997; Williams, 2006; Carter, 2002; Pearce, 2009; Katorski, 2003). "Communication satisfaction is described as fulfillment of expectations" (carter, 2002). Carter (2005) found out that "securely attached daughter's had higher communication satisfaction than avoidant daughters. Securely attached daughters communicate with their fathers for certain motives, such as affection, pleasure, relaxation, inclusion. Similarly fathers communicate with their daughters for certain motives, such as, affection, pleasure and relaxation."Also carter (2005), found out that "communication motives of relaxation and pleasure predicted communication satisfaction in daughter." Thus it can be predicted that securely attached daughter's expectations of relaxation and pleasure aremet when they communicate with their fathers and thus feel communicatively satisfied.

Father's involvement in daughter's development also seems to helps her grow intellectually, "Raddin (1918b), in her research found out that daughter's mental age increases and she scores well in cognitive tasks, than uninvolved father's daughter. In another study she found out that daughters of involved fathers score well on verbal intelligence, however, this study also suggest that though fathers are involved with the positive development of their daughters, they are more involved with their sons intellectual growth, suggesting that even highly involved fathers direct more attention to sons than to daughters" (Veneziano, 2004).

\section{New fathers are more involved}

Nielsen (2012) believes that "average fathers are not involved with their daughters." Which seems to be almost true, but now it seems as if more and more number of Indian fathers are waking to the fact that their involvement is necessary and essential for their daughter's development and overall growth. This trend seems to be mainly visible in middle income urban families. As can be seen from the researches, for instance, research done by "roopnarine, talukder, jain, joshi and srivastav $(1990,1992)$ suggest that middle income fathers from dualearner families are more involved with their children than fathers used to be in the past" (Sharma, 2003). Another study done by "Anjula Saraf on Indian fathers suggest that Indian men are moving away from the image of traditional father (economic provider, family head, role model) to the new father who is participating in childcare activity culturally not expected of them." (Yeung, 2010).However this study also found that thought the transition is taking place from traditional father to new father; fathers are more confused with their roles, i.e. though father's perception regarding their roles is changing but their conduct is not in exact synchrony with their perception. The author suggests an urgent need to educate fathers regarding their roles.

\section{CONCLUSION}

The father-daughter attachment pattern predicts daughter's development in many ways. The secure attachment pattern predicts "communication satisfaction, communication adaptability, 
higher self-esteem, social competence, social understanding, interpersonal differentiation and emotional regulation" (Pleck, 1997; Williams, 2006; Carter, 2002; Pearce, 2009; Katorski, 2003). Whereas, the insecure attachment pattern predicts low social competence, social understanding, self-esteem, communication satisfaction, interpersonal differentiation, emotional regulation and communication adaptability" (Pleck, 1997; Williams, 2006; Carter, 2002; Pearce, 2009; Katorski, 2003). The reasons for father's less interaction and less involvement seem to be rooted in the assumption that fathers when play more defined and traditional role of an 'economic source', tend to be more detached from their children especially girl child. It has been seen that trend is changing; "fathers seem to be more involved in their children's life than some decades ago as suggested by a research done byroopnarine, talukder, jain, joshi and srivastav (1990, 1992)" (Sharma, 2003).From the above evidences the importance of positive relationship of daughter with her father can be predicted. Thus, it can be said that there are things which father only can adequately provide, as there are things that only mother can provide. Thus, father-daughter secure attachment pattern is important in many ways.

\section{LIMITATION}

This paper is not perfect and has certain limitations. First limitation of this study is that it does not take into account the factors that influence the development of daughters other than her relationship with her father. Second, this paper doesn't take into account the psychoanalytic perspective that extensively talks about father-daughter relationship.

\section{IMPLICATION FOR FUTURE RESEARCH}

This topic has scope for future research. More comprehensive research can be done considering the other factors such as socio-economic status, different cohort group, studying father-daughter relationship in light of other relationships such as mother, other children and may be grandparents, which are not addressed in this paper. An empirical research can be done in Indian context to understand the prevalence of secure attachment between father and daughter.

\section{REFERENCES}

1. Berk, L. (2013). Child Development. Delhi: PHI learning private limited.

2. Boothroyd, L. G., \& Perrett, D. I. (2008). Father Absence, Parent-Daughter. Journal of Evolutionary Psychology, 187-205.

3. Carter, N. M. (december, 2005). Father and Daughter Motives and. Communication Research Reports .

4. Carter, N. M. (2002). Using Attachment Theory to Study Satisfaction in Father-Daughter Relationships. Human Communication. A Publication of the Pacific and Asian Communication Association Vol. 10, No. 2 , pp. 103 - 120.

5. Finello, K. (n.d.). parents. Retrieved from http://www.parents.com/parenting/betterparenting/style/the-role-of-fathers-with-daughters-and-sons/ 
6. Grogan, G. L. (n.d.). The Relation between Attachment to Opposite Sex.

7. Jackson, L. M. (2010). Where's my daddy? Effects of fatherlessness on women's relational communication. Master's Theses .

8. katorski. (2003). Father/Daughter Relationships: Effects of Communicative Adaptability and Satisfaction on Daughter's Romantic Relationships. journal of undergraduate research .

9. Knight, A. (2008). yahoo! voices. Retrieved from http://voices.yahoo.com/correctinginsecure-attachment-styles-due-father-1712917.html?cat $=25$

10. Nielsen, L. (2012). Father-Daughter: Contemporary Research. New York: Taylor \& Francis Group.

11. Pearce, C. (2009). Daughter-to-father attachment, daughter-to-mother.

12. Scheffler, T. S., \& Naus, P. J. (1999). The relationship between fatherlyaffirmation. The Canadian Journal of Human Sexuality, Vol. 8(1) Spring , 39-45.

13. Sharma, D. (2003). Childhood, Family, and Sociocultural Change In India. New Delhi: Oxford University Press.

14. Veneziano, R. (2004). Parental Role. In: Ember C., Ember (Deceased) M. (Ed.) . encyclopedia of sex and gender-men and women in the world's cultures .

15. Williams, C. M. (2006). An exploration of father-child relationships.

16. Yeung, W. J. (2010). International Conference on Fatherhood in 21st Century Asia: Research, Interventions, and Policies. 